Western University

Scholarship@Western

Mechanical and Materials Engineering

Mechanical and Materials Engineering

Publications

Department

2016

\title{
A conjugate fluid-porous approach to convective heat and mass transfer with application to produce drying
}

Furqan A. Khan

The University of Western Ontario

Anthony G. Straatman

uwo, agstraat@uwo.ca

Follow this and additional works at: https://ir.lib.uwo.ca/mechanicalpub

Part of the Materials Science and Engineering Commons, and the Mechanical Engineering Commons

Citation of this paper:

Khan, Furqan A. and Straatman, Anthony G., "A conjugate fluid-porous approach to convective heat and mass transfer with application to produce drying" (2016). Mechanical and Materials Engineering

Publications. 14.

https://ir.lib.uwo.ca/mechanicalpub/14 


\title{
A conjugate fluid-porous approach to convective heat and mass transfer with application to produce drying
}

\author{
Furqan Ahmad Khan", Anthony Gerald Straatman \\ Department of Mechanical \& Materials Engineering, Western University, London, Ontario, N6A 5B9, Canada
}

\section{A R T I C L E I N F O}

\section{Article history:}

Received 31 July 2015

Received in revised form

25 January 2016

Accepted 31 January 2016

Available online 3 February 2016

\section{Keywords:}

Computational fluid dynamics (CFD)

Heat transfer

Mass transfer

Convective drying

Porous material

Conjugate modeling

\begin{abstract}
A B S T R A C T
A computational model capable of simulating heat and mass transfer in conjugate fluid-porous domains is utilized to simulate forced convective drying. The material to be dried is considered as the porous region, which is coupled through interfaces to the surrounding pure fluid region. The computational model solves transport equations for mass and momentum, energy, and moisture in all regions simultaneously. The model includes non-equilibrium heat and moisture transport in the porous region such that the fluid and solid constituents, and the exchanges between them, are captured. The interfacial moisture transfer condition between phases in the porous region, and between the porous and pure fluid regions, is developed to show the level of detail required for modeling. The study considers the drying of apple flesh to validate the developed drying model against available experimental data. The results show accurate prediction of moisture content as a function of drying time for different airflow velocities, and correctly capture the influences of temperature, relative humidity and initial moisture content on the drying rate. Thus, the model is considered viable for taking steps towards implicit dynamic coupling of the constituents in the porous region.
\end{abstract}

(C) 2016 Elsevier Ltd. All rights reserved.

\section{Introduction}

Convective drying of porous materials is of interest due to its applicability in engineering applications such as building materials production, processing and dehydration of foods, paper production, among others (Defraeye et al., 2012a). The porous materials to be dried in such applications range from bricks, concrete and wood to fruits, vegetables, and grains. Such materials can be classified based on their hygroscopic nature. For example, potato, carrot, wood, etc. are hygroscopic materials (Srikiatden and Roberts, 2005; Stanish et al., 1986), while, sand, ceramic, etc. are considered to be nonhygroscopic (Stanish et al., 1986).

In convective drying of porous materials, air with low relative humidity is forced across (and through) a wet porous media. Because of its capacity to hold fluids in their vapour state, the air absorbs moisture as it flows across the porous material, which results in drying or dehydration. The capacity of the airstream to take on moisture increases with increasing temperature (and viceversa), and has its upper threshold for a given temperature at the

\footnotetext{
* Corresponding author.

E-mail address: fkhan72@uwo.ca (F.A. Khan).
}

dew-point, which is defined by $100 \%$ relative humidity. The porous material to be dried consists of a solid structure (or solid matrix), water, and void space (Sereno et al., 2007). The moist air comprised of dry air and water vapour - occupies the void space (Sereno et al., 2007), and the liquid water can be considered to be held inside the microstructure of the solid component of the porous material. As such, moisture transport in the form of water vapour and liquid water occurs inside the porous materials (Defraeye et al., 2012b; Murugesan et al., 2001; Suresh et al., 2001; Younsi et al., 2008). Thus, complete modeling of a drying process requires the consideration of (moist) air passing across the material to be dried with dynamic coupling between the constituents to enable exchanges of heat and moisture to evolve based on local conditions (i.e. temperature, water activity, etc.)

Numerical modeling has been widely used to simulate convective drying. Previous numerical models can be broadly classified into categories based on their level of sophistication. In this respect, the most basic are drying curve models (see, for example Akpinar et al., 2003; Demir et al., 2007; Menges and Ertekin, 2006; Seiiedlou et al., 2010), which utilize a single moisture equation to evaluate moisture loss from a porous material as a function of temperature and other parameters. These models provide overall drying rates, however, they are not capable of accounting for the 
local variations of different quantities inside the porous domain.

The next category of models use differential energy and moisture transport equations to model the drying process inside the porous domain (see, for example Barati and Esfahani, 2011a, 2011b, 2013; Golestani et al., 2013; Kumar et al., 2012; Perussello et al., 2014; Srikiatden and Roberts, 2008; Younsi et al., 2006). As a result, these models predict the local variations of temperature and moisture content inside the drying material by solving a single equation for each of energy and moisture transport. The transport equations employed, in general, contain only unsteady and diffusion terms, and Fourier and Fick's Laws are used to model diffusion in the energy and moisture equations, respectively. In such models, convective boundary conditions are imposed at the surface of the material to be dried. In this respect, convective heat and mass transfer coefficients are evaluated using empirical correlations based on $\mathrm{Nu}=\mathrm{f}(\mathrm{Re}, \mathrm{Pr})$ and $\mathrm{Sh}=\mathrm{f}(\mathrm{Re}, \mathrm{Sc})$, which means that the simulation results are dependent upon the empirical correlations used.

The third category of models enables improvement in the evaluation of convective heat and mass transfer inside the porous domain. Such models (see, for example Ateeque et al., 2014; Esfahani et al., 2014; Kaya et al., 2006; Mohan and Talukdar, 2010; Tzempelikos et al., 2015) solve single energy and moisture transport equations inside the drying material, but also consider the fluid region surrounding the material, although not in a directcoupled, conjugate manner. The surrounding airflow is first resolved by solving the mass and momentum transport equations along with the transport equation of energy to calculate the heat transfer coefficient at the surface of the material. The thermal and concentration boundary layer analogy is then used to compute the surface mass transfer coefficient. The evaluated coefficients are then utilized to impose convective boundary conditions at the material's surface to obtain a solution inside the drying material. The term "non-conjugate approach" is often used to refer to this category of models (Defraeye et al., 2012a).

While the non-conjugate approach considers one domain at a time, a conjugate approach involves simultaneous modeling of both the drying material and the surrounding airflow region. These models introduce mathematical conditions to enforce continuity of heat and mass transfer at the fluid-porous interface, which eliminates the requirement for imposing convective heat and mass transfer coefficients between regions of the domain. The conjugate models proposed by Lamnatou et al. (2010) and Sabarez (2012) use single energy and moisture transport equations for each region to model energy and mass transfer. In this respect, it is the effective heat and moisture transport that is solved for, and the temperature and mass fraction characterize the local conditions. This approach is suitable for predicting temperature and moisture distributions in the porous region, but local transport between the phases of the porous media are not provided.

When the material subjected to drying is comprised of a micro-porous solid structure and void space, which is generally the case for biologically derived systems, moisture transport occurs mainly due to capillary forces, pressure gradients, and temperature gradients (Suresh et al., 2001; Younsi et al., 2008). In such cases, it becomes important to account for both the vapour and liquid transport inside the porous material. In this respect, several studies (Defraeye et al., 2012b; Erriguible et al., 2006; Murugesan et al., 2001; Steeman et al., 2009; Suresh et al., 2001; Younsi et al., 2008) focused on convective drying of porous materials using a conjugate approach, except that moisture transfer inside the drying material was modeled by combining the vapour and water transport into a single moisture transport equation. The work of De Bonis and Ruocco (2008) took a non-equilibrium approach to mass transport by employing separate vapour and water transport equations inside the drying material, but they did not consider advection or thermal nonequilibrium inside the porous material. Defraeye et al. (2012b), Younsi et al. (2008), Erriguible et al. (2006), and Perré and Turner (1999) have utilized volume-averaged energy and moisture transport equations. In addition, Erriguible et al. (2006), and Perré and Turner (1999) considered the advection term in the energy and moisture transport equations, and used Darcy's Law to calculate the flow velocity inside porous material.

The literature survey reveals that a majority of the most advanced prior work models heat and mass transport inside the porous materials or porous solids (Defraeye et al., 2012b; Murugesan et al., 2001; Suresh et al., 2001; Younsi et al., 2008) using single energy and moisture transport equations. In other words, the fluid and solid-constituents in a given cell inside the porous media are generally characterized using single temperature and fluid mass-fraction values. This approach is found to provide reasonable results for temperature and moisture distributions and for overall drying times, provided the effective transport coefficients for heat and mass are carefully calibrated. However, such an approach is not capable of predicting local exchanges of energy and moisture between constituents inside a cell. The main objective of the present work is to demonstrate the capability of the proposed formulation to accurately simulate the convective drying process of porous materials. Moreover, the proposed framework is generic and can be applied to wide range of porous materials. In this respect, the present work utilizes a conjugate domain approach, wherein mass, momentum, energy, and moisture transport equations are solved in the fluid and porous region. The model also accounts for thermal and mass non-equilibrium in the porous region such that both the vapour and water exchanges between the constituents are considered. In this respect, we further demonstrate that a conjugate, nonequilibrium model can provide information necessary to make the next important step towards direct, dynamic coupling of the phases.

Modeling of the porous material at this level of detail requires thermophysical properties of both the fluid and solid constituents, as well as quantification of the key geometric parameters of the porous material. To the best of authors' knowledge, no study, as yet, has provided such a level of detail of the porous material even though such characterization is essential for modeling the different mechanisms of heat and moisture transport inside the porous region and at the fluid-porous interface. The present study models the interfacial moisture transfer using a circuit analogy, which accounts for all interfacial exchanges, and additional parameters required to achieve the physical moisture thresholds observed in the convective drying process. The performance of the complete model is assessed by application to the drying of apple flesh. In this respect, the results of Velić et al. (2004) are used as a reference.

\section{Formulation}

As described earlier, the airflow surrounding the porous material plays a crucial role in the convective drying process. From the numerical modeling perspective, moist air can be considered as a mixture of dry air (comprised of all the gaseous components) and water vapour. The vapour content of the moist airflow is evaluated by solving a transport equation in the form of vapour mass fraction $\left(Y_{v}\right)$. The moist air is then treated as a mixture of dry air and water vapour, and its flow is evaluated by solving the conventional massmomentum transport equations. The moist air density $\left(\rho_{f}\right)$ used in the transport equations is continuously updated to account for the moisture gain/loss of the air by the expression 
$\rho_{f}=\rho_{a}+\rho_{v}=\frac{P_{a}}{R_{a} T}+\frac{P_{v}}{R_{v} T}$

where, $P_{a}$ is the partial pressure of dry air, $P_{v}$ is the vapour partial pressure, $R_{a}$ and $R_{v}$ are the air and vapour gas constants, respectively. The moist air temperature $(T)$ is obtained by solving the energy transport equation. Complete details on the calculation of $\rho_{f}$ can be found in Khan et al. (2015).

Since the present study models the convective drying using a conjugate approach, we present the transport equations required in both the fluid and porous regions along with the fluid-porous interface conditions.

\subsection{Fluid region}

In the fluid region, the mass and momentum conservation equations for the air-water vapour mixture are expressed as

$\frac{\partial \rho_{f}}{\partial t}+\nabla \cdot\left(\rho_{f} \mathbf{v}\right)=0$

$\frac{\partial\left(\rho_{f} \mathbf{v}\right)}{\partial t}+\nabla \cdot\left(\rho_{f} \mathbf{v v}\right)=-\nabla P+\mu_{f} \nabla^{2} \mathbf{v}+\rho_{f} \mathbf{f}$

The transport equation for the mass fraction of water vapour is expressed as (Bird et al., 2007)

$\frac{\partial\left(\rho_{f} Y_{v}\right)}{\partial t}+\nabla \cdot\left(\rho_{f} Y_{v} \mathbf{v}\right)=\nabla \cdot\left(\rho_{f} D_{f} \nabla Y_{v}\right)+S_{v}$

The energy transport equation of the air-water vapour mixture takes a form to account for the latent energy of water vapour evaporation. In this respect, we consider that the specific enthalpy of each species is the sum of sensible and latent energy components, which can be expressed as

$h_{i}=c_{p, i} T+h_{f g, i}$

where, $i$ represents the species number. Since we have two species in the present formulation, $i=1$ (dry air) and 2 (water vapour), and the latent component for dry air is $h_{f g, 1}=0$. The total specific enthalpy of the air-water vapour mixture is obtained by summing the specific enthalpy of dry air and water vapour. Using Eq. (5), the energy transport of the moist air in the fluid region takes the form

$$
\begin{aligned}
& \sum_{i} c_{p, i} \frac{\partial\left(\rho_{f} Y_{i} T\right)}{\partial t}+\sum_{i} h_{f g, i} \frac{\partial\left(\rho_{f} Y_{i}\right)}{\partial t}+\sum_{i} c_{p, i} \nabla \cdot\left(\rho_{f} Y_{i} T \mathbf{v}\right) \\
& \quad+\sum_{i} h_{f g, i} \nabla \cdot\left(\rho_{f} Y_{i} \mathbf{v}\right) \\
& =k_{f} \nabla^{2} T+\sum_{i} \nabla \cdot\left[\rho_{f} D_{f} \nabla Y_{i}\left(c_{p, i} T+h_{f g, i}\right)\right]+S_{e}
\end{aligned}
$$

Energy transfer due to the unsteady effects is represented by the first two terms on the left hand side of Eq. (6). The third and fourth terms on the left hand side account for energy transfer caused by advection. On the right hand side, the first term accounts for conduction, while the second term represents energy transfer due to species diffusion.

\subsection{Porous region}

In the porous region, volume-averaging of the transport equations is carried out to characterize the porous material as porous continuum. The process of volume-averaging involves integration of the transport equations over a representative elementary volume of porous material. The volume-averaging of a quantity $\varphi_{f}$, as described in Whitaker (1997), is carried out as

$\left\langle\varphi_{f}\right\rangle=\frac{1}{V} \int_{V_{f}} \varphi_{f} d V$

where, $V$ represents the volume over which the averaging is conducted, $V_{f}$ is the volume of fluid inside $V$, and $\left\langle\varphi_{f}\right\rangle$ is termed as the extrinsic-average of $\varphi_{f}$. In the similar fashion, an intrinsic-averaged quantity $\left\langle\varphi_{f}\right\rangle^{f}$ can be expressed as

$\left\langle\varphi_{f}\right\rangle^{f}=\frac{1}{V_{f}} \int_{V_{f}} \varphi_{f} d V$

The porosity $\varepsilon$ of the porous material is then defined as $\varepsilon=\left\langle\varphi_{f}\right\rangle /\left\langle\varphi_{f}\right\rangle^{f}$. Complete details of the closed-forms of Eqs. (2)-(4) and (6) can be found in Khan et al. (2015) and is not repeated herein. The volume-averaged mass and momentum conservation equations take the form

$$
\begin{aligned}
& \varepsilon \frac{\partial\left\langle\rho_{f}\right\rangle^{f}}{\partial t}+\nabla \cdot\left(\left\langle\rho_{f}\right\rangle^{f}\langle\mathbf{v}\rangle\right)=0 \\
& \frac{\partial\left(\left\langle\rho_{f}\right\rangle^{f}\langle\mathbf{v}\rangle\right)}{\partial t}+\frac{1}{\varepsilon} \nabla \cdot\left(\left\langle\rho_{f}\right\rangle^{f}\langle\mathbf{v}\rangle\langle\mathbf{v}\rangle\right) \\
& \quad=-\varepsilon \nabla\langle P\rangle^{f}+\mu_{f} \nabla^{2}\langle\mathbf{v}\rangle+\varepsilon\left\langle\rho_{f}\right\rangle^{f} \mathbf{f}-\frac{\varepsilon \mu_{f}}{K}\langle\mathbf{v}\rangle-\frac{\varepsilon\left\langle\rho_{f}\right\rangle^{f} c_{E}}{\sqrt{K}}|\langle\mathbf{v}\rangle|\langle\mathbf{v}\rangle
\end{aligned}
$$

where the last two terms on the right hand side of Eq. (10), are closure terms referred to as Darcy and Forchheimer terms, respectively. These two terms represent viscous (Darcy) and form (Forchheimer) drag experienced by the fluid as it flows through the porous material.

The present model considers a non-equilibrium approach for moisture and energy transport inside the porous material, which means that separate energy and moisture transport equations are employed for each of the fluid and solid-constituents of the porous media. As mentioned previously, the porous materials considered consist of a solid-structure (or solid-matrix), water, and voids. In the present study, the solid-constituent is considered to be holding water within its interconnected micro-pores, while the void space characterized by the volume fraction $\varepsilon$ contains the air-water vapour mixture (fluid-constituent). Water transport inside the solid-constituent is evaluated by solving a water mass fraction $\left(Y_{w}\right)$ transport equation. For the fluid-constituent, the volume-averaged version of Eq. (4) is included in the formulation. Thus, the present formulation considers both the water and water vapour transport inside the porous material. The extrinsically volume-averaged moisture transport equations for the fluid and solid-constituents, respectively, are expressed as

$$
\begin{gathered}
\varepsilon \frac{\partial\left(\left\langle\rho_{f}\right\rangle^{f}\left\langle Y_{v, f}\right\rangle^{f}\right)}{\partial t}+\nabla \cdot\left(\left\langle\rho_{f}\right\rangle^{f}\left\langle Y_{v, f}\right\rangle^{f}\langle\mathbf{v}\rangle\right) \\
\quad=\nabla \cdot\left(\left\langle\rho_{f}\right\rangle^{f} D_{e f f, f} \nabla\left\langle Y_{v, f}\right\rangle^{f}\right)+\varepsilon S_{v, f}+\left\langle\dot{m}_{f s}\right\rangle
\end{gathered}
$$




$$
\begin{aligned}
(1-\varepsilon) \frac{\partial\left(\left\langle\rho_{s}\right\rangle^{s}\left\langle Y_{w, s}\right\rangle^{s}\right)}{\partial t}= & \nabla \cdot\left(\left\langle\rho_{s}\right\rangle^{s} D_{e f f, s} \nabla\left\langle Y_{w, s}\right\rangle^{s}\right)+(1-\varepsilon) S_{w, s} \\
& -\left\langle\dot{m}_{f s}\right\rangle
\end{aligned}
$$

The last two terms on the right hand side of Eqs. (11) and (12), account for the interfacial moisture transfer between the fluid and solid-constituents inside the porous material. The evaluation of $\left\langle\dot{m}_{f s}\right\rangle$ is based on the water content available within the solidconstituent. First, the maximum amount of $\left\langle\dot{m}_{\mathrm{fs}}\right\rangle$ is evaluated as (Kaviany, 1995)

$\left\langle\dot{m}_{f s}\right\rangle=\left\langle\rho_{f}\right\rangle^{f} h_{f s m} A_{f s}\left(\left\langle Y_{v}\right\rangle^{f_{s}}-\left\langle Y_{v, f}\right\rangle^{f}\right)$

where, $\left\langle Y_{v}\right\rangle^{f_{s}}$ quantifies the vapour mass fraction at the surface of the solid-constituent, which is evaluated by considering the surface to be saturated with vapor; i.e. relative humidity of $100 \%$. If the available water content is less than the $\left\langle\dot{m}_{f_{s}}\right\rangle$ calculated using Eq. (13) then $\left\langle\dot{m}_{f_{s}}\right\rangle$ is computed based on the available water content (see Khan et al. (2015) for details).

Similar to the transport equations for moisture, the extrinsically volume-averaged energy transport equations for the fluid and solid-constituents, respectively, are given as

$$
\begin{aligned}
& \sum_{i} \varepsilon c_{p, i} \frac{\partial\left(\left\langle\rho_{f}\right\rangle^{f}\left\langle Y_{i, f}\right\rangle^{f}\left\langle T_{f}\right\rangle^{f}\right)}{\partial t}+\sum_{i} \varepsilon h_{f g, i} \frac{\partial\left(\left\langle\rho_{f}\right\rangle^{f}\left\langle Y_{i, f}\right\rangle^{f}\right)}{\partial t} \\
& +\sum_{i} c_{p, i} \nabla \cdot\left(\left\langle\rho_{f}\right\rangle^{f}\left\langle Y_{i, f}\right\rangle^{f}\left\langle T_{f}\right\rangle^{f}\langle\mathbf{v}\rangle\right) \\
& +\sum_{i} h_{f g, i} \nabla \cdot\left(\left\langle\rho_{f}\right\rangle^{f}\left\langle Y_{i, f}\right\rangle^{f}\langle\mathbf{v}\rangle\right)=k_{e f f, f} \nabla^{2}\left\langle T_{f}\right\rangle^{f} \\
& +\sum_{i} \nabla \cdot\left[\left\langle\rho_{f}\right\rangle^{f} D_{e f f, f} \nabla\left\langle Y_{i, f}\right\rangle^{f}\left(c_{p, i}\left\langle T_{f}\right\rangle^{f}+h_{f g, i}\right)\right] \\
& +\varepsilon S_{e, f}+h_{f s} A_{f s}\left(\left\langle T_{s}\right\rangle^{s}-\left\langle T_{f}\right\rangle^{f}\right)
\end{aligned}
$$

$N u_{f s}=C_{T} \operatorname{Re}_{d_{p}}^{0.5} \operatorname{Pr}^{0.37}=\frac{h_{f s} d_{p}}{k_{f}}$

$S h_{f s}=C_{m} R e_{d_{p}}^{0.5} S c^{0.37}=\frac{h_{f s m} d_{p}}{D_{f}}$

where, in the present case $C_{T}$ and $C_{m}$ are held constant at 100.0 and 0.005 , respectively. In the case of no airflow i.e. $R e_{d_{p}}=0, h_{f s}$ and $h_{f s m}$ also become zero using Eqs. (16) and (17). However, in such case, the diffusive transport still exists between the fluid and solidconstituents. Therefore, the lower limit of the interfacial coefficients is evaluated based on the local diffusion coefficients as $h_{f s}=k_{\text {eff. } f}$ and $h_{f s m}=D_{\text {eff. } f}$.

\subsection{Interface conditions}

The interface conditions between the fluid and porous regions of the conjugate domain connect the fluid and porous regions and ensure that momentum, energy and mass transfer occurs smoothly across the interfaces.

At the fluid-porous interface, the continuity of the airflow velocity and pressure are enforced as (Betchen et al., 2006)

$\mathbf{v}_{f l}=\langle\mathbf{v}\rangle_{\text {por }}$

$P_{f l}=\langle P\rangle_{p o r}$

Comprehensive discussions on the hydrodynamic interface conditions expressed in Eqs. (18) and (19) can be found in Betchen et al. (2006). The thermal energy transfer at the fluid-porous interface is expressed as (Betchen et al., 2006)

$$
\left(-k_{f} \frac{\partial T}{\partial \boldsymbol{n}}\right)_{f l}=\left(-k_{e f f . f} \frac{\partial\left\langle T_{f}\right\rangle^{f}}{\partial \boldsymbol{n}}-k_{e f f, s} \frac{\partial\left\langle T_{s}\right\rangle^{s}}{\partial \boldsymbol{n}}\right)_{p o r}
$$

The above expression implies that heat transfer from the fluid region splits at the fluid-porous interface to be transported into the fluid and solid-constituents of porous media. The energy split is quantified based on the different thermal conductivity and temperature gradients appearing in Eq. (20).

$\sum_{i}(1-\varepsilon) c_{p s, i} \frac{\partial\left(\left\langle\rho_{s}\right\rangle^{s}\left\langle Y_{i, s}\right\rangle^{s}\left\langle T_{s}\right\rangle^{s}\right)}{\partial t}=k_{e f f, s} \nabla^{2}\left\langle T_{s}\right\rangle^{s}+\sum_{i} \nabla \cdot\left[\left\langle\rho_{s}\right\rangle^{s} D_{e f f, s} \nabla\left\langle Y_{i, s}\right\rangle^{s}\left(c_{p s, i}\left\langle T_{s}\right\rangle^{s}\right)\right]+(1-\varepsilon) S_{e, s}-h_{f s} A_{f s}\left(\left\langle T_{s}\right\rangle^{s}-\left\langle T_{f}\right\rangle^{f}\right)$

Since Eq. (15) represents energy transport inside the solidconstituent (solid-structure holding water), it does not include the latent energy terms. The last two terms of Eqs. (14) and (15) model the interfacial heat transfer between the fluid and solidconstituents. The sensible energy of water before evaporation in the fluid-phase energy equations (Eqs. (6) and (14)) is accounted for by modeling the source term as $S_{e}=h_{w a t e r}\left\langle\dot{m}_{f s}\right\rangle$. The enthalpy of water $\left(h_{\text {water }}\right)$ is defined using the local temperature.

Here, it becomes necessary to calculate the local interfacial heat and mass transfer coefficients $\left(h_{f s}\right.$ and $h_{f s m}$ ) appearing in Eqs. (11), (12), (14) and (15). In the present formulation, these coefficients are found using the following expressions (Calmidi and Mahajan, 2000)
In the convective drying of porous materials, the treatment of moisture transfer at the fluid-porous interface is critical. The continuity of moisture transfer at the fluid-porous interface is enforced as

$$
\left(-\rho_{f} D_{f} \frac{\partial Y_{v}}{\partial \boldsymbol{n}}\right)_{f l}=\left(-\left\langle\rho_{f}\right\rangle^{f} D_{e f f, f} \frac{\partial\left\langle Y_{v, f}\right\rangle^{f}}{\partial \boldsymbol{n}}-\left\langle\rho_{s}\right\rangle^{s} D_{e f f, s} \frac{\partial\left\langle Y_{w, s}\right\rangle^{s}}{\partial \boldsymbol{n}}\right)_{p o r}
$$

For elaboration, Eq. (21) is expressed using a circuit analogy at the pore-level scale in Fig. 1, which shows that the moisture transport split at the interface is dictated by four resistances driven by moisture mass fractions. Since the nodal values of moisture mass 


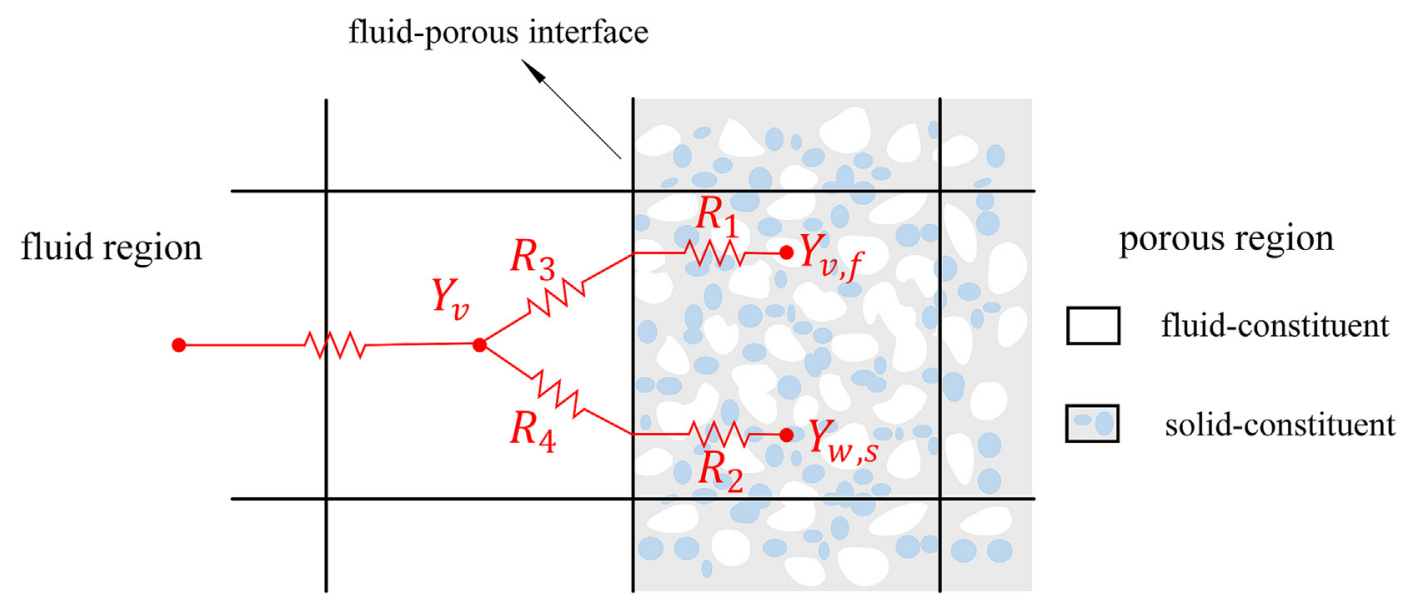

Fig. 1. Illustration of fluid-porous moisture transfer interface condition using resistance analog at pore-level scale along with the grid.

fractions are part of the solution, it is essential to correctly model the four resistances, which requires proper evaluation of the different density and mass diffusivity coefficients given in Eq. (21). Thus, while this treatment of the interface is general to heat and mass transfer across conjugate domains, its application requires knowledge of many parameters.

The complete conjugate formulation described in this section is suitable for modeling non-equilibrium energy and mass transport in conjugate domains of all scales. The formulation inherently provides the capability to couple the phases inside the volumeaveraged porous domain and thereby express the local transport in terms of the local conditions. While this approach is extremely thorough in terms of the level of prediction, it requires the specification of transport coefficients that are not required in equilibrium models. The remainder of this article elaborates on application of this model formulation to predict the drying of apple flesh, as this provides an opportunity to show how the various coefficients are obtained and demonstrates the capability of the present model.

\section{Convective drying of apple flesh}

The convective drying of apple flesh is selected to demonstrate the capabilities of the proposed framework. In this respect, the highly-referenced work of Velić et al. (2004) is utilized because it provides all the necessary information required to simulate the drying process. The experimental study of Velić et al. (2004) focused on convective drying of $20 \times 20 \times 5 \mathrm{~mm}$ rectangular apple slices (with peel removed) to study the effects of airflow velocity on the heat transfer and mass diffusivity coefficients. The computational domain considered in the present modeling effort takes advantage of symmetry in two directions and includes a quarter of an apple slice, plus a portion of the surrounding region where moist air flows (see Fig. $2 a-b$ ). Consequently, the porous region representing the apple has dimensions of $20 \times 10 \times 2.5 \mathrm{~mm}$ in the $x, y$, and $z$-directions, respectively. The fluid regions in each direction around the slice are obtained by a boundary position study to ensure that their position does not affect predictions in the region of interest. The resulting fluid-porous domain used in the simulations is $40 \times 20 \times 7.5 \mathrm{~mm}$ in $x, y$, and $z$-directions, respectively.

Structured hexahedral control-volumes (CV) were used to discretize the domain. During the grid convergence testing, the grid was refined from $20 \times 15 \times 15$ to $30 \times 20 \times 20$ and $40 \times 30 \times 30$ CVs in $x, y$, and $z$-directions, respectively. The grid containing $30 \times 20 \times 20 \mathrm{CV}$ was selected for the simulations because
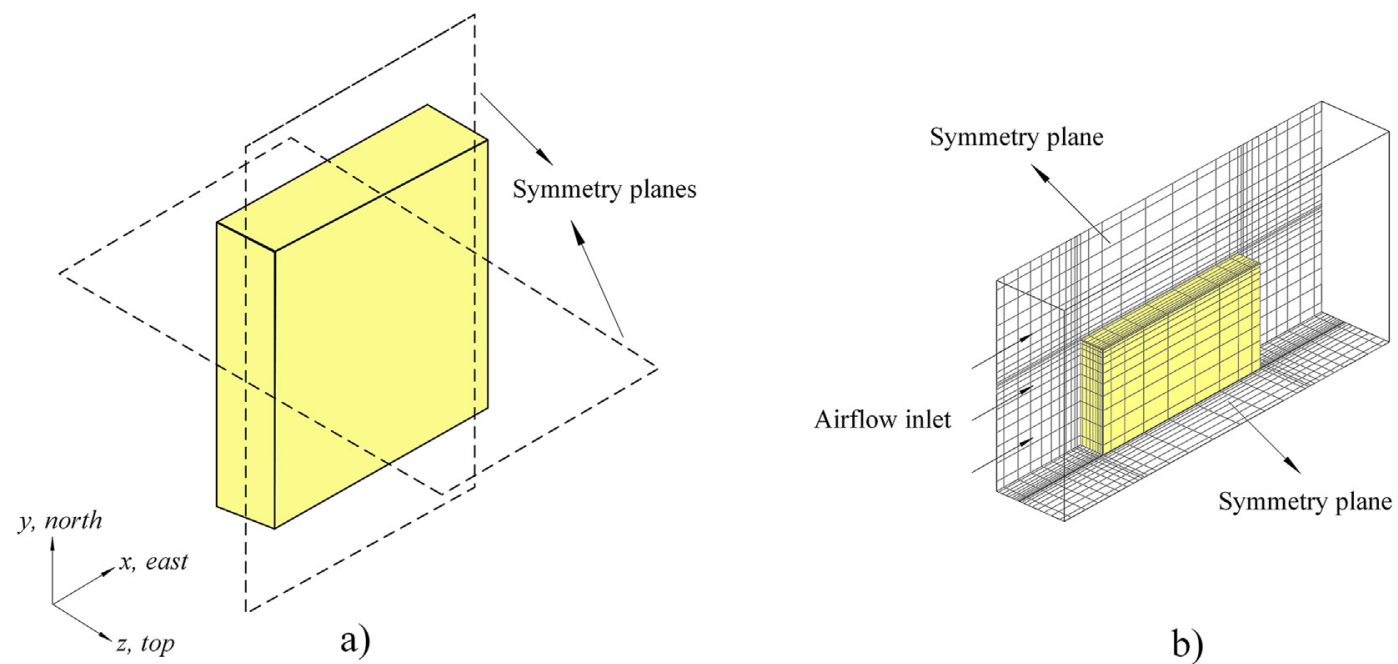

b)

Fig. 2. a) Apple slice geometry and orientation along with the symmetry planes; b) meshed fluid-porous domain used for the convective drying simulations. 
refinement to $40 \times 30 \times 30 \mathrm{CV}$ produced a maximum change of $0.12 \%$ in the predicted moisture content. To ensure the solution accuracy, the grid is refined in the vicinity of all fluid-porous interfaces. The meshed domain used for the simulations is shown in Fig. 2b.

The transport equations were discretized using finite volume approach. In brief, the Rhie-Chow approach was used to maintain pressure-velocity coupling, while UDS and QUICK were implemented to model advection in the fluid and porous domains. The interested reader is directed to Khan et al. (2015) for a full description of the discretization details. The solution advances in time to simulate the unsteady convective drying process. The solution proceeds to the next time-step when the maximum normalized residual of all the transport equations falls below $5 \times 10^{-6}$ at the current time-step. A time-step size of $50 \mathrm{~s}$ is utilized to advance in time as the reduction in the time-step size from 50 to $5 \mathrm{~s}$ changes the moisture content by only $0.13 \%$. Furthermore, for the purpose of solution accuracy and stability, the time-step size is gradually increased from 0.02 to $50 \mathrm{~s}$ at the beginning of the simulation. Initial conditions are discussed in a subsequent subsection describing properties.

The boundary conditions for the conjugate domain shown in Fig. $2 \mathrm{~b}$ are as follows:

Airflow inlet: The moist airflow enters the domain at $60^{\circ} \mathrm{C}$ with a relative humidity of $9 \%$; the airflow velocity is varied from 0.64 to $2.75 \mathrm{~m} / \mathrm{s}$. These inlet conditions are imposed to simulate the results of Velić et al. (2004). The inlet pressure is extrapolated from the domain interior.

Outlet (east face): zero normal derivative condition is imposed for all velocity components, temperature, and moisture mass fraction. The outlet pressure is fixed at atmospheric pressure (101.3 kPa).

Symmetry plane (south face): zero normal derivative condition is enforced on all the variables, excluding the $v$ velocity component, which is set to zero to ensure zero mass flux.

Symmetry plane (bottom face): zero normal derivative condition is imposed on all the variables, apart from the $w$ velocity component, which is equal to zero to ensure zero mass flux.

North and top faces: for all the velocity components, temperature, and moisture mass fraction, zero normal derivative condition is imposed to minimize the boundary condition effects on the solution. The pressure is extrapolated from the interior of the domain.

To assess the drying airflow regime, we evaluated the flow Reynolds number based on the largest dimension of the apple slice $(20 \mathrm{~mm})$. For the airflow velocity of $2.75 \mathrm{~m} / \mathrm{s}$, the Reynolds number was found to be below 3500 , which ensures that the drying airflows simulated in the present work fall in the laminar regime.

\subsection{Modeling of apple flesh as a porous material}

Modeling of apple flesh as a porous material involves determination of thermophysical properties of the fluid and solidconstituents along with the geometric parameters of the porous material (apple). These properties are necessary for consideration of apple flesh as a porous material. Note that the procedure described in this study is generic and can be applied to other produce or moist porous materials. In addition, this section also covers the moist airflow properties required to simulate the drying process.

As discussed earlier, apple flesh is composed of solid and fluidconstituents. The solid-constituent is considered herein to be comprised of the solid-structure and liquid water, while the fluidconstituent consists of voids filled with moist air. At this point, we recall Eq. (21) and define the solid-constituent density $\left\langle\rho_{s}\right\rangle^{s}$ as
$\left\langle\rho_{s}\right\rangle^{S}=\alpha_{s t} \rho_{S t}+\alpha_{w} \rho_{w}$

where, $\alpha_{s t}$ and $\alpha_{w}$ are the volume fractions of the solid-structure and water, respectively, and $\rho_{s t}$ and $\rho_{w}$ represent the density of the solid-structure and water, respectively.

Information on the volume fractions and densities shown in Eq. (22) are required to calculate $\left\langle\rho_{s}\right\rangle^{s}$. The density of water $\left(\rho_{w}\right)$ is wellknown, however, $\rho_{s t}, \alpha_{s t}$ and $\alpha_{w}$ are often difficult to obtain. During the drying process, $\rho_{s t}$ and $\alpha_{s t}$ are assumed constant, while $\alpha_{w}$ is updated continuously utilizing the latest water mass fraction $\left(Y_{w}\right)$. To our advantage, the existing literature contains information on the apple moisture content $(X)$, which is described as the ratio of mass of water to the mass of dry matter (solid-structure) (Lozano et al., 1980). The averaged moisture content can be normalized by $X^{0}$, which represents the moisture content prior to the drying process. The local moisture content can be calculated as

$X=\frac{\alpha_{w} \rho_{w}}{\alpha_{s t} \rho_{S t}}$

To evaluate $\rho_{s t}, \alpha_{s t}$ and $\alpha_{w}$, Eqs. (22) and (23) are solved simultaneously, with the assumption that prior to the drying process the sum of $\alpha_{s t}$ and $\alpha_{w}$ is equal to one. In this respect, the values of $\left\langle\rho_{s}\right\rangle^{s}$ and $X$ prior to drying are required. Lozano et al. (1980) and Rahman (1995) describe different density definitions accounting for various aspects of porous materials. In the present study, we consider $\left\langle\rho_{s}\right\rangle^{s}$ as substance density, which represents the density of material without pores or voids. For the evaluation, $\left\langle\rho_{s}\right\rangle^{s}$ and $X^{0}$ are set as $1055 \mathrm{~kg} / \mathrm{m}^{3}$ (O'Neill et al., 1998) and $7.45 \mathrm{~kg}$ water $/ \mathrm{kg}$ dry matter (Lozano et al., 1980), respectively. The evaluated properties of the apple flesh along with the other required properties are presented in Table 1. The thermal conductivity of the fluid and solidconstituents presented in Table 1 are obtained as $K_{\text {eff }, f}=\varepsilon \times K_{\text {apple }}$ and $K_{\text {eff }, s}=(1-\varepsilon) \times K_{\text {apple }}$, where $K_{\text {apple }}$ is obtained from Donsi et al. (1996). The specific heat of the solidstructure $\left(c_{p s}\right)$ is obtained in a similar manner using the apple

Table 1

Fluid and porous regions properties.

\begin{tabular}{|c|c|}
\hline \multicolumn{2}{|l|}{ Air } \\
\hline$c_{p}[\mathrm{~J} /(\mathrm{kg} \mathrm{K})]$ & 1005 \\
\hline$R[\mathrm{~J} /(\mathrm{kg} \mathrm{K})]$ & 287 \\
\hline \multicolumn{2}{|l|}{ Water vapour } \\
\hline \multicolumn{2}{|c|}{ (Cengel and Boles, 2008) } \\
\hline$c_{p}[\mathrm{~J} /(\mathrm{kg} \mathrm{K})]$ & 1872 \\
\hline$h_{f g}[\mathrm{~J} / \mathrm{kg}]$ & $2500 \times 10^{3}$ \\
\hline$R[\mathrm{~J} /(\mathrm{kg} \mathrm{K})]$ & 461.5 \\
\hline \multicolumn{2}{|c|}{ Fluid mixture } \\
\hline \multicolumn{2}{|c|}{ (Incropera et al., 2006; Tsilingiris, 2008) } \\
\hline$D_{f}\left[\mathrm{~m}^{2} / \mathrm{s}\right]$ & $2.600 \times 10^{-5}$ \\
\hline$k_{f}[\mathrm{~W} /(\mathrm{m} \mathrm{K})]$ & 0.0258 \\
\hline$\mu_{f}\left[\mathrm{~N} \cdot \mathrm{s} / \mathrm{m}^{2}\right]$ & $1.830 \times 10^{-5}$ \\
\hline \multicolumn{2}{|l|}{ Porous material } \\
\hline \multicolumn{2}{|c|}{$\begin{array}{l}\text { (Betchen et al., 2006; Donsi et al., 1996; Feng et al., 2004; } \\
\text { Incropera et al., 2006; Lozano et al., 1980; Mykhailyk } \\
\text { and Lebovka, 2014; Yu et al., 2006) }\end{array}$} \\
\hline$A_{f s}\left[\mathrm{~m}^{-1}\right]$ & 11,650 \\
\hline$K\left[\mathrm{~m}^{2}\right]$ & $8.89 \times 10^{-13}$ \\
\hline$\varepsilon$ & 0.206 \\
\hline$d_{p}[\mu \mathrm{m}]$ & 103 \\
\hline$c_{p s}[\mathrm{~J} /(\mathrm{kg} \mathrm{K})]$ & 252 \\
\hline$c_{p w}[\mathrm{~J} /(\mathrm{kg} \mathrm{K})]$ & 4180.0 \\
\hline$k_{\text {eff } f}[\mathrm{~W} /(\mathrm{m} \mathrm{K})]$ & 0.0865 \\
\hline$k_{e f f, s}[\mathrm{~W} /(\mathrm{m} \mathrm{K})]$ & 0.3335 \\
\hline$\rho_{s t}\left[\mathrm{~kg} / \mathrm{m}^{3}\right]$ & 1811.53 \\
\hline$\rho_{w}\left[\mathrm{~kg} / \mathrm{m}^{3}\right]$ & 999.0 \\
\hline$\alpha_{s t}$ & 0.0689 \\
\hline$\alpha_{w}$ & 0.9311 \\
\hline
\end{tabular}


specific heat provided by Mykhailyk and Lebovka (2014). The pore diameter $d_{p}$ is obtained using the Ergun equation (Yu et al., 2006). In the present study, $\varepsilon$ represents the volume fraction of the fluidconstituent (voids). Moreover, the present formulation neglects the shrinkage, which results in constant $\varepsilon$ during the simulated drying process. Although, the model does account for the voids created due to the removal of water from the solid-constituent. The specific interfacial surface area of porous material $\left(A_{f s}\right)$ is calculated using $\varepsilon$ and $d_{p}$ of the porous material.

At this point, we define the initial conditions of the convective drying simulation. The initial water mass fraction $\left(Y_{w}\right)$ of the apple is evaluated as 0.881 by employing $X^{0}$ provided by Lozano et al. (1980). In addition, the fluid and porous regions initial temperatures are set to $60^{\circ} \mathrm{C}$.

It is important to note that Table 1 lists all the properties required to model the apple flesh as a porous material, with the exception of effective solid and fluid-constituent mass diffusivity coefficients $\left(D_{\text {eff,s }}\right.$ and $\left.D_{\text {eff.f }}\right)$. In the convective drying process, these coefficients have significant importance, as evident from Eq. (21). These coefficients characterize the diffusive transport of vapour and water inside the porous media and transport the moisture to the porous surface to be picked up by the surrounding airflow. In the existing literature, no study, as yet, has evaluated $D_{\text {eff,s }}$ and $D_{\text {eff. } f}$ values for non-equilibrium moisture transfer inside the porous material. Herein, we utilize available information to evaluate $D_{\text {eff,s }}$

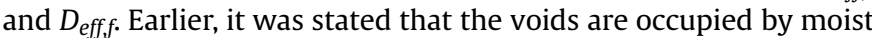
air, which means that the diffusivity coefficient of air-vapour mixture $D_{f}$ can be utilized to evaluate $D_{\text {eff.f. }}$ In this respect, as a reasonable approximation, $D_{\text {eff } f}$ is calculated as $D_{\text {eff } f}=D_{f} \times \varepsilon$.

The evaluation of $D_{e f f, s}$ is done using the moisture resistance circuit shown in Fig. 1. At this point, it becomes essential to more clearly describe the four resistances given in the figure. $R_{1}$ and $R_{2}$ are responsible for vapour and water diffusive transport from the fluid and solid-constituents of the porous media, respectively, up to the fluid-porous interface. The vapour and water transported at the interface are then exchanged with the fluid region by $R_{3}$ and $R_{4}$, respectively. These four resistances can be calculated using the harmonic mean formulation described by Betchen et al. (2006), and are expressed as
(2004). Here, we arbitrarily select the case where the airflow velocity is $0.64 \mathrm{~m} / \mathrm{s}$, for which $D_{\text {eff }}$ increases from $1.70 \times 10^{-9}$ to $2.91 \times 10^{-9} \mathrm{~m}^{2} / \mathrm{s}$ during the drying process. The simulation produces moisture removal rates that are in excellent agreement to the corresponding rates reported by Velić et al. (2004). Moreover, the simulation provides the numerical value of $R_{s, i}$ at the fluid-porous interface, which is then employed to calculate $D_{\text {eff,s }}$ by fixing $D_{f}$. In the present case, $D_{f}$ (value provided in Table 1 ) represents the mass diffusivity coefficient of the air-vapour mixture surrounding the porous material. The purpose of using a single diffusivity coefficient value for $D_{f}, D_{\text {eff,s, }}$, and $D_{\text {eff } f}$ in the simulation is to obtain the correct numerical value of $R_{s, i}$. In other words, this simulation calibrates $R_{s, i}$ to the correct value, which is then utilized to calculate the correct value of $D_{\text {effs. }}$. While this may appear as over-calibration, it is extremely difficult to measure such values experimentally, so such an approach is warranted.

In addition to $R_{S, i}$, the simulation also provides the diffusive resistance to water transport inside the solid-constituent $\left(R_{S}\right)$ and the diffusive resistance to vapour transport inside the fluidconstituent $\left(R_{f}\right)$ of the porous material. The simulation reveals that, during the entire drying process, $R_{f}$ is higher than $R_{S}$ by more than two orders of magnitude. Such a considerable difference between $R_{f}$ and $R_{S}$ means that fluid-constituent transport inside the porous material only weakly participates in the drying process. Moreover, it also suggests that it is more important to have the correct value of $D_{\text {eff,s }}$ compared to $D_{\text {eff.f. }}$ The comparison in magnitude between $R_{S, i}$ and $R_{S}$ shows that throughout the drying process $R_{s, i}$ stays greater than $R_{S}$ by at least one order of magnitude, which means that $R_{s, i}$ acts like a barrier to moisture transfer at the fluidporous interface. Furthermore, $R_{S}$ increases in time due to the reduction in moisture content within the porous material. It is also found that, at a given instant in time, the local moisture content decreases as we move towards the fluid-porous interface from the inner porous region. Consequently, it is appropriate to consider that the solid-constituent surface exposed to the surrounding airflow is comparatively dry and hinders the removal of moisture from the porous material. This phenomenon of a dry solid-constituent surface forming an additional moisture resistance is also discussed by Defraeye et al. (2012b). This additional hindrance to moisture

$$
R_{1}=\frac{\Delta x_{i-p}}{A\left\langle\rho_{f}\right\rangle^{f} D_{e f f . f}}, \quad R_{2}=\frac{\Delta x_{i-p}}{A\left\langle\rho_{s}\right\rangle^{s} D_{e f f, s}}, \quad R_{3}=\frac{\Delta x_{f-i}}{\varepsilon A \rho_{f} D_{f}}, \quad R_{4}=\frac{\Delta x_{f-i}}{(1-\varepsilon) A \rho_{f} D_{f}}
$$

where, $\Delta x_{f-i}$ is the distance between the node in the fluid region and the interface, and $\Delta x_{i-p}$ is the distance between the interface and the porous region node, and $A$ is the total area of the control volume face adjacent to the interface. Note that the effects of porosity in $R_{1}$ and $R_{2}$ are absorbed by $D_{\text {eff. } f}$ and $D_{\text {eff,s, }}$, respectively. The total diffusive transport resistance of water between the fluid and porous nodes across the interface is obtained by adding $R_{2}$ and $R_{4}$. The resulting resistance $\left(R_{s, i}\right)$ is expressed as

$R_{s, i}=\frac{\Delta x_{i-p}}{A\left\langle\rho_{s}\right\rangle^{s} D_{e f f, s}}+\frac{\Delta x_{f-i}}{A(1-\varepsilon) \rho_{f} D_{f}}$

For the evaluation of $D_{\text {eff,s, }}$ a case of convective drying is simulated while keeping $D_{f}, D_{\text {eff,s, }}$, and $D_{\text {eff. } f}$ set to the effective diffusivity coefficient of the drying process $\left(D_{\text {eff }}\right)$ obtained from Velić et al. transfer at the interface is modeled by introducing a resistance coefficient $\left(C_{s i}\right)$. The modified expression for $R_{s, i}$ is then given as

$R_{s, i}=\frac{C_{s i} \Delta x_{i-p}}{A\left\langle\rho_{s}\right\rangle^{s} D_{e f f, s}}+\frac{\Delta x_{f-i}}{A(1-\varepsilon) \rho_{f} D_{f}}$

An iterative approach is used to converge to a realistic value of $C_{s i}$. We start with $C_{s i}=1$ to calculate $D_{e f f, s}$, which is then used to simulate the drying process. $C_{s i}$ is then modified until the simulation produces drying rates that are in reasonable agreement with the results of Velić et al. (2004). The computed $D_{\text {eff,s }}$ as the function of moisture content is presented in Fig. 3, which shows that, unlike $D_{f}$ and $D_{\text {eff., },} D_{\text {eff,s }}$ is not constant and changes throughout the process of drying. The increasing pattern of $D_{\text {eff.s }}$ is primarily attributed to the diminishing value of $\left\langle\rho_{s}\right\rangle^{s}$ as evident from Eq. (26). Cubic 


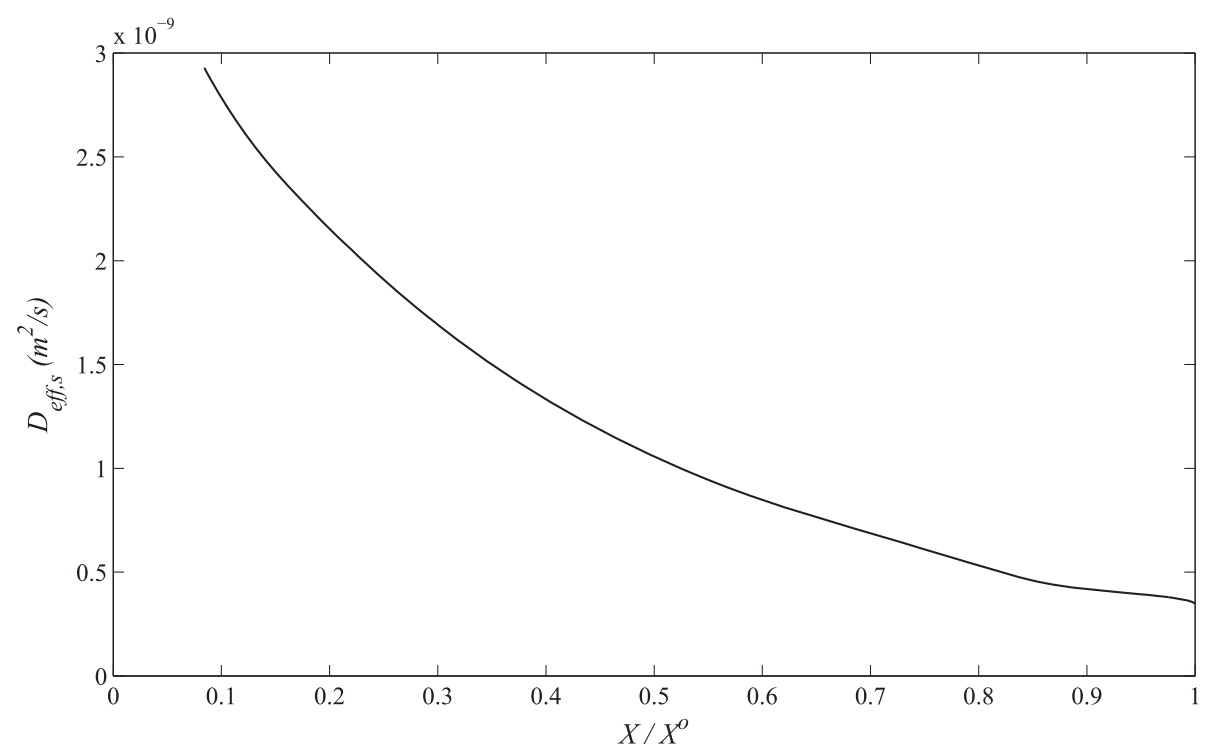

Fig. 3. Evaluated $D_{\text {eff,s }}$ as the function of the moisture content.

polynomial curve-fitting is utilized to input $D_{\text {eff,s }}$ as the function of local moisture content throughout the porous domain.

One final point in terms of modeling concerns the adherence to thresholds of moisture transport, which are required for the model to work correctly under a full range of airflow conditions. The basic concept is that once the drying airflow becomes completely saturated with vapour - that is, having relative humidity of $100 \%-$ then it should not pick up any further moisture from the porous material. In terms of vapour pressure, such condition exists when the airflow vapour pressure $\left(P_{v}\right)$ becomes equal to the water saturation pressure $\left(P_{g}\right)$ at a given temperature. For this reason, the modeling is carried out in the fluid region adjacent to the fluidporous interface. In this respect, the moisture condition at the fluid-porous interface (Eq. (21)) is again utilized. The total diffusive transport resistance of water across the fluid-porous interface $\left(R_{s, i}\right)$ is given by Eq. (26). In a similar way, $R_{1}$ and $R_{3}$ are added together to formulate the total diffusive transport resistance of vapour between the fluid and porous nodes across the interface $\left(R_{f, i}\right)$, which is expressed as

$R_{f, i}=\frac{\Delta x_{i-p}}{A\left\langle\rho_{f}\right\rangle^{f} D_{e f f . f}}+\frac{\Delta x_{f-i}}{\varepsilon A \rho_{f} D_{f}}$

In the present formulation, we create a moisture threshold by introducing an additional resistance coefficient $\left(C_{f i}\right)$ in $R_{3}$ and $R_{4}$. The resulting $R_{s, i}$ and $R_{f, i}$ are expressed as

$R_{s, i}=\frac{C_{s i} \Delta x_{i-p}}{A\left\langle\rho_{s}\right\rangle^{s} D_{e f f, s}}+\frac{C_{f i} \Delta x_{f-i}}{A(1-\varepsilon) \rho_{f} D_{f}}$

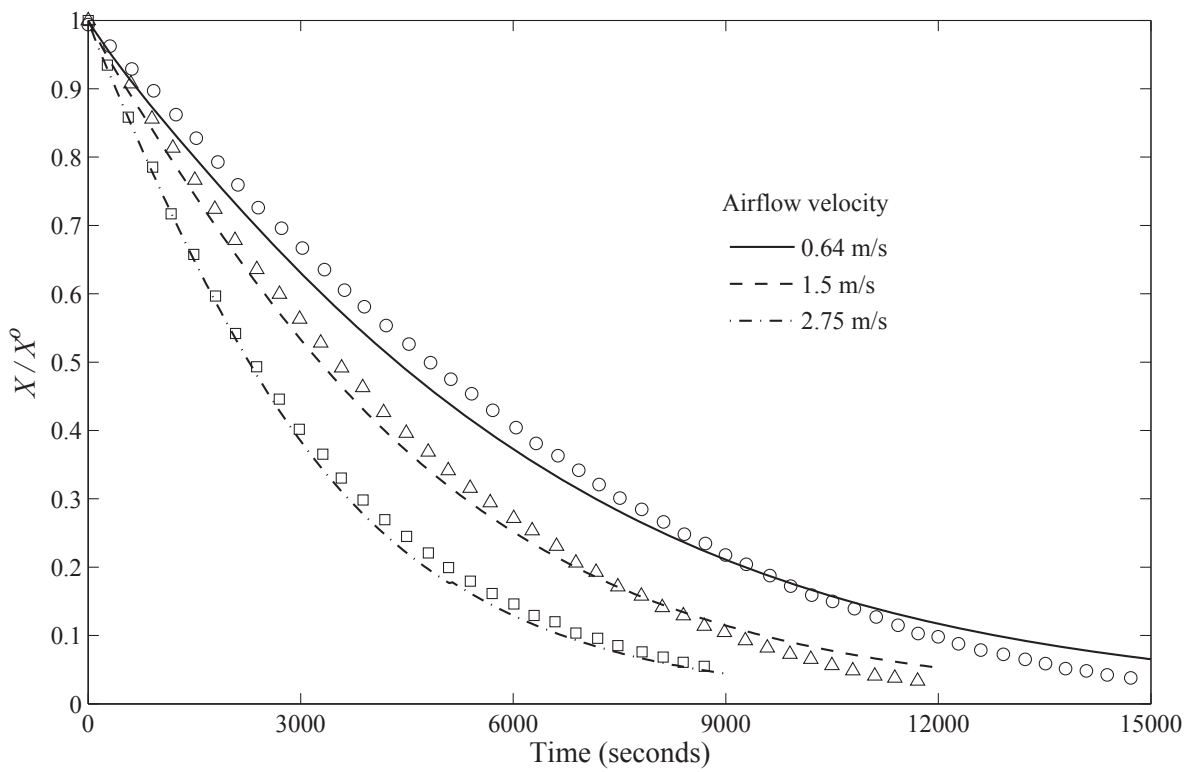

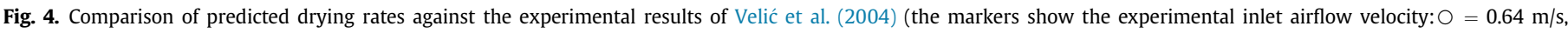
$\triangle=1.5 \mathrm{~m} / \mathrm{s}$ and $\square=2.75 \mathrm{~m} / \mathrm{s}$ ). 


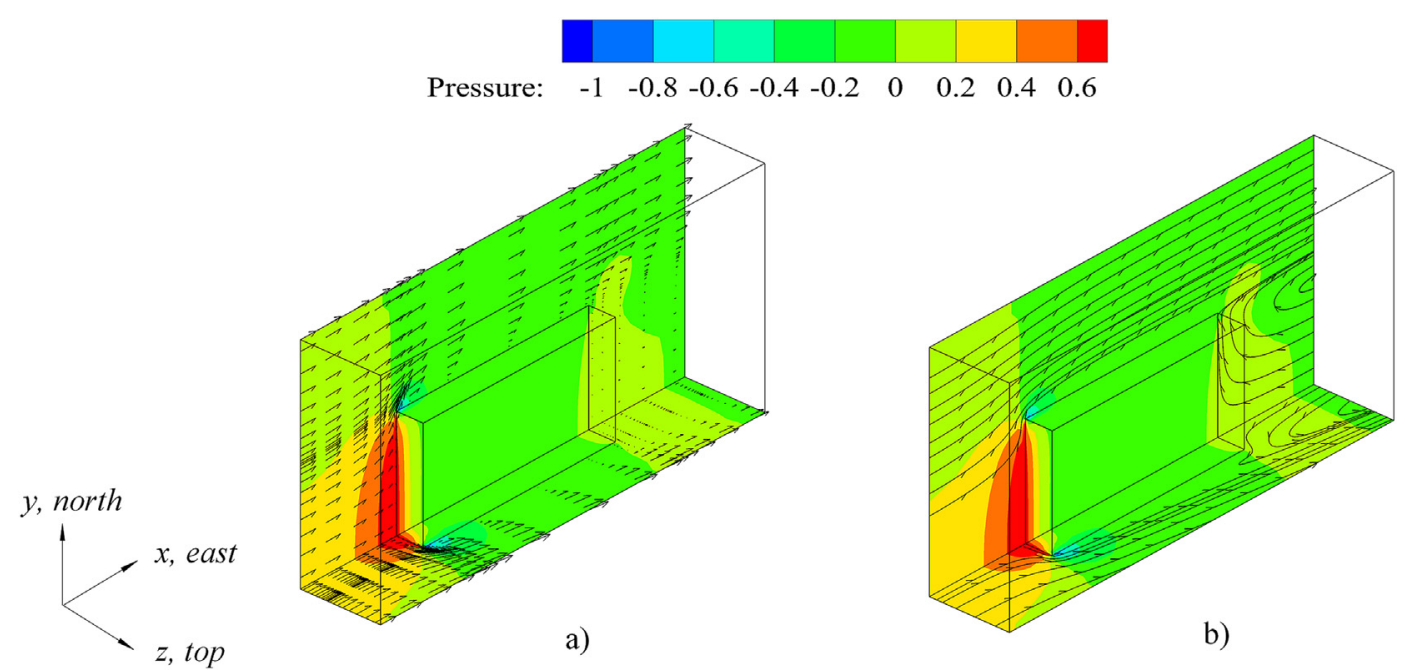

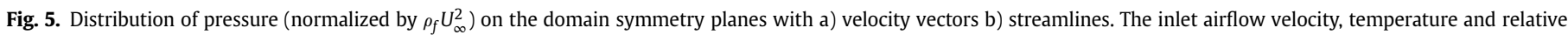
humidity are $0.64 \mathrm{~m} / \mathrm{s}, 60{ }^{\circ} \mathrm{C}$ and $9 \%$, respectively.

$R_{f, i}=\frac{\Delta x_{i-p}}{A\left\langle\rho_{f}\right\rangle^{f} D_{\text {eff. } f}}+\frac{C_{f i} \Delta x_{f-i}}{\varepsilon A \rho_{f} D_{f}}$

We model the resistance coefficient $C_{f i}$ as the function of airflow vapour and saturation pressures. In this respect, the validated cases presented in Fig. 4, which have airflow relative humidity of $9 \%$ at $60{ }^{\circ} \mathrm{C}$, are considered as a reference having $C_{f i}=1$. Moreover, $C_{f i}$ should approach the maximum value at $100 \%$ relative humidity of airflow to completely cease the drying process. Based on such requirements, $C_{f i}$ is evaluated as
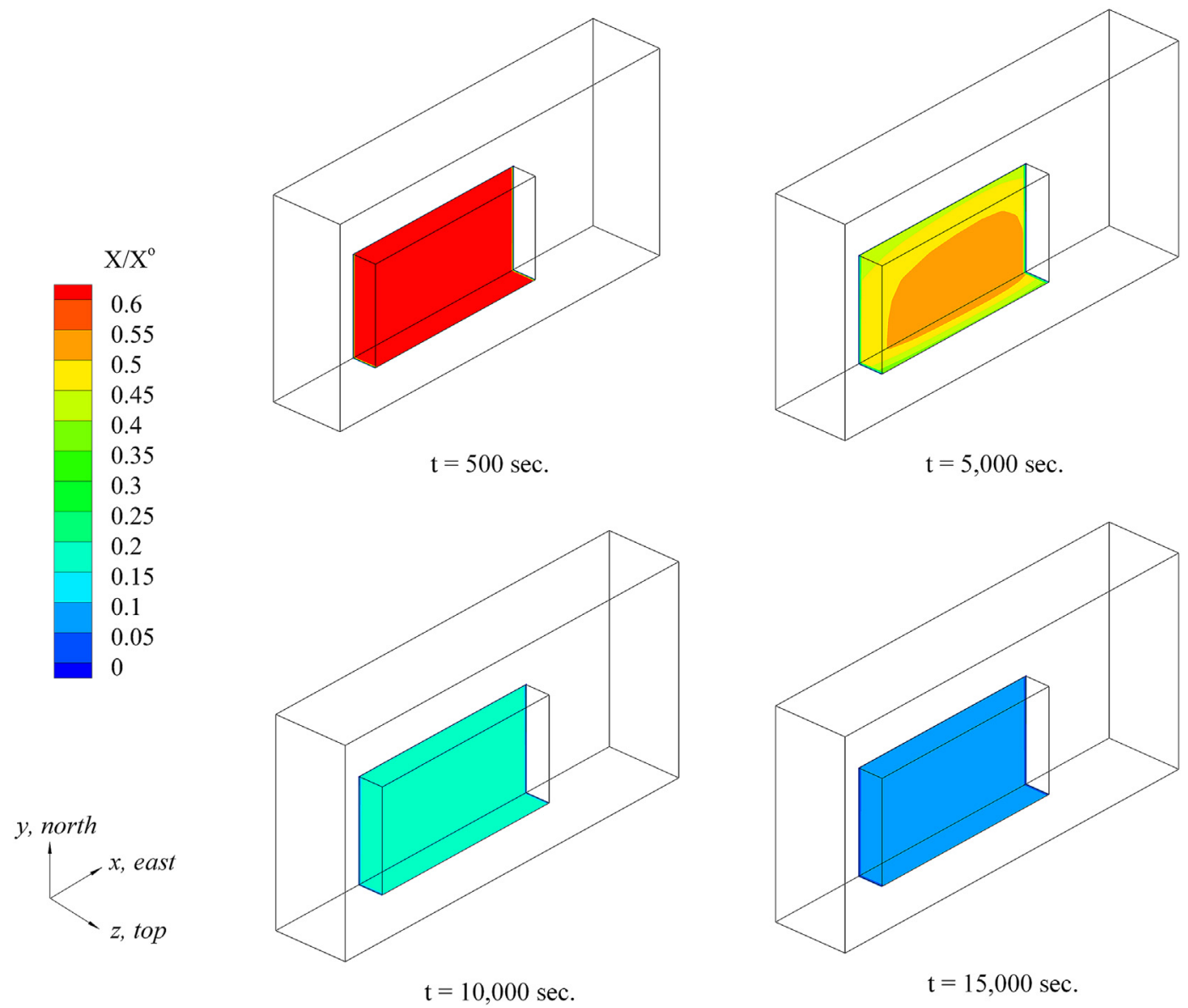

$\mathrm{t}=15,000 \mathrm{sec}$.

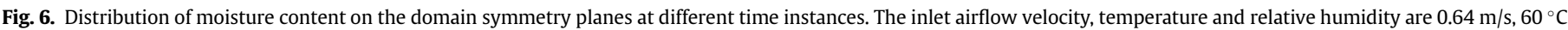
and $9 \%$, respectively. 

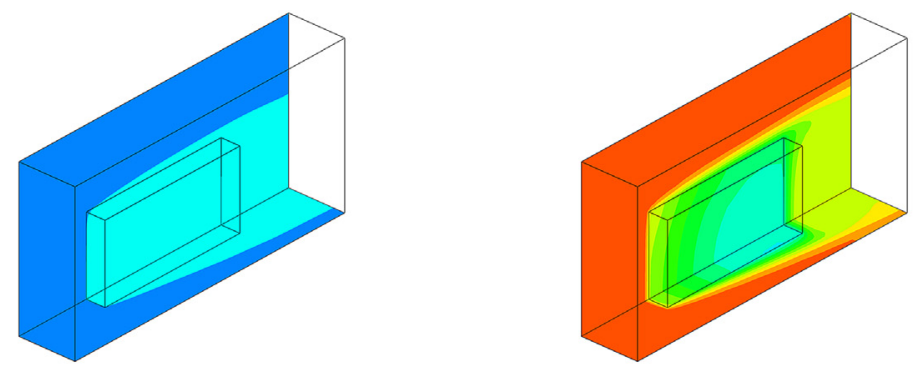

Inlet relative humidity $=9 \%$

Relative Humidity
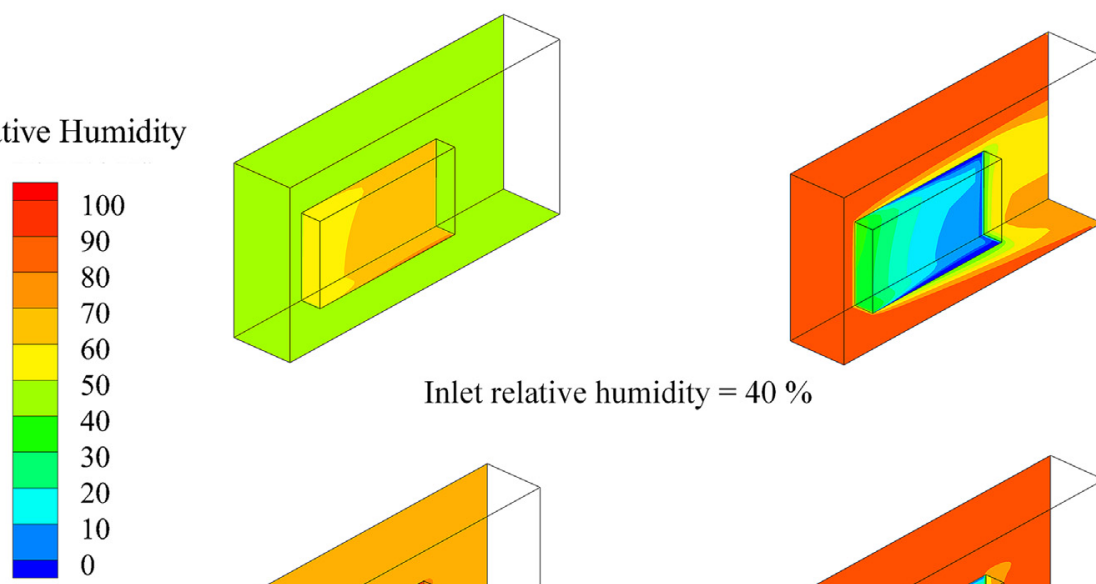

Inlet relative humidity $=40 \%$
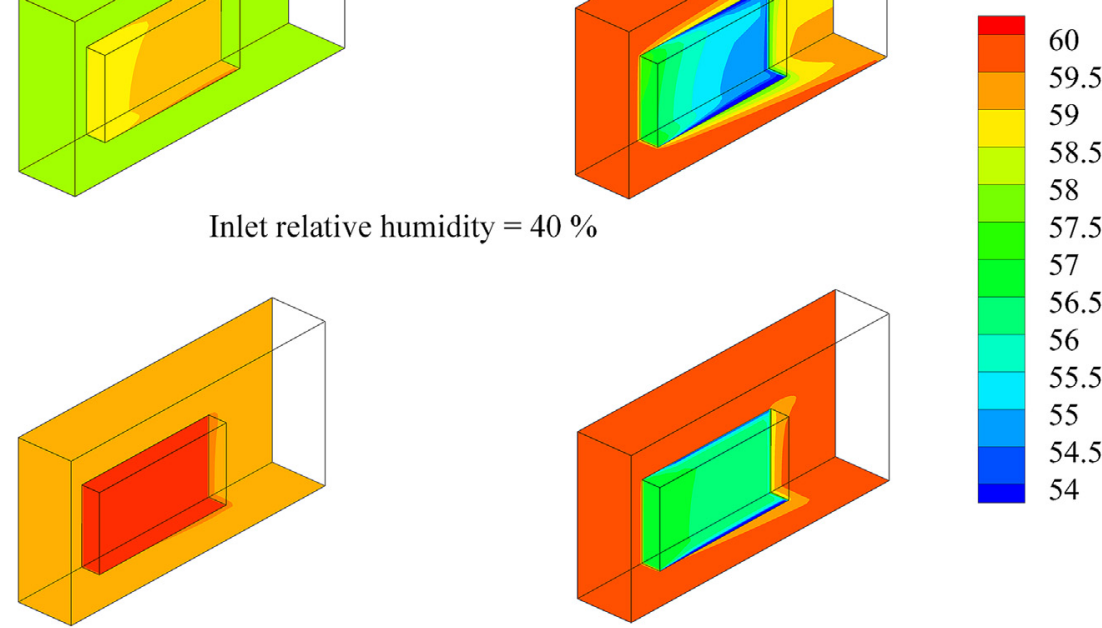

Inlet relative humidity $=70 \%$
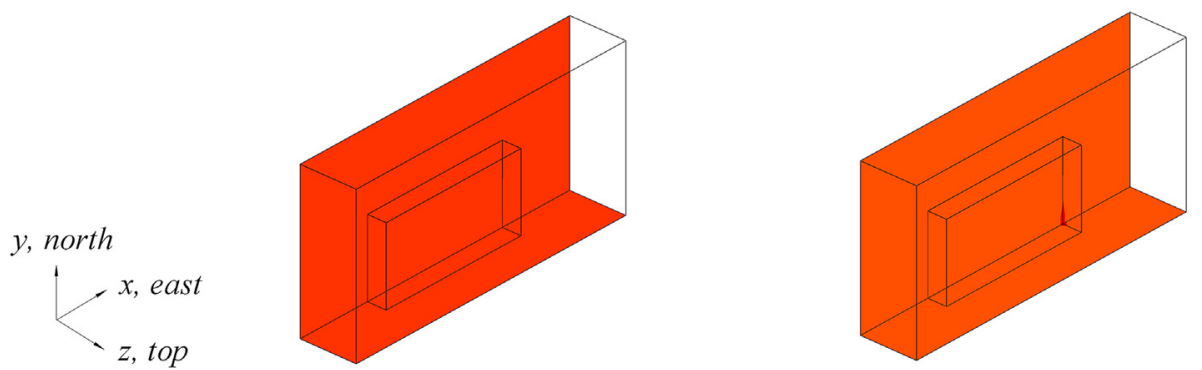

Inlet relative humidity $=100 \%$

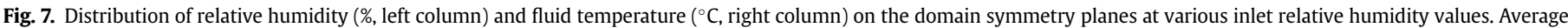

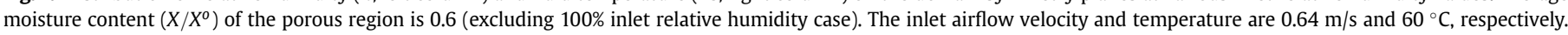

$C_{f i}=c^{b}\left(1-\frac{\Delta P}{\Delta P_{\text {ref }}}\right)$

where, $\Delta P=P_{g}-P_{v}$. The evaluation of $\Delta P$ is carried out at the node in the fluid region adjacent to the fluid-porous interface. The $P_{g}$ as the function of temperature is evaluated using Antoine equation for water vapour (NIST, 2011). The $\Delta P_{\text {ref, }}$ which is evaluated using the validated cases, is found equal to $15.8 \mathrm{kPa}$. Moreover, the constants $c$ and $b$ are set as 5.85 and 10.0 , respectively. It is important to mention that the expression used to calculate $C_{f i}$ in Eq. (30) is not calibrated using the experimental results. In the present work, its sole purpose is to ensure that the formulation predicts the correct moisture threshold.

With all the evaluated properties, we now demonstrate the viability of the proposed model formulation and property treatment in a convective drying process and show that the influences of various quantities are properly predicted using the calibrated model. As mentioned earlier, the present results are validated using the results of Velić et al. (2004), who reported results over the airflow velocity range of $0.64-2.75 \mathrm{~m} / \mathrm{s}$. Over this range, Velić et al. (2004) reported an increment in $D_{\text {eff }}$ with increasing airflow 
velocity. To account for this variation, a process similar to that described above is used to obtain $C_{s i}=860,540$, and 330 for velocities of $0.64,1.5$, and $2.75 \mathrm{~m} / \mathrm{s}$, respectively. The simulated results for the moisture content of the apple slice are shown in Fig. 4. The results show excellent agreement with the work of Velić et al. (2004). While not shown in the figures, several computational cases at varying inlet air temperatures and relative humidity confirmed that the trends in drying time are correctly predicted, and that the imposed thresholds for moisture transport take effect for saturated air.

While it might be argued that the agreement is due to the property evaluation approach and the calibration used for the interface treatment, it is critical to note that those steps only form a small part of the simulation strategy. The purpose of this study is to show that the conjugate domain formulation utilizing a complete flow simulation, combined with thermal and mass non-equilibrium can be used to accurately simulate a drying operation. The formulation is generic and extensive, and has not been simplified to take advantage of the low permeability of the apple flesh or the near-thermal equilibrium of the solid and fluid phases inside the flesh. While simplifications could have been made in the simulations presented, one of the main objectives of the study was to demonstrate the value of using the complete framework, since this is required when using a dynamic phase-coupled approach, which is also possible using the present formulation. The most important result from the present case study is the accurate prediction of both the drying rates and the rate-of-change of drying rates during the process. The present formulation also permits a detailed look in and around the porous domain, as described below.

Fig. 5 shows pressure contours and velocity vectors and streamlines on the symmetry planes of the domain. The plot shows that the incoming air flows almost entirely around the porous material as opposed to flowing through it, an expected result, since the apple slice has a very low permeability and behaves almost like a solid material. Though not seen in Fig. 5, weak values of all three velocity components are predicted inside the apple flesh due to the pressure difference in the mean flow direction. Fig. 5 also shows the wake behind the slice, which is characterized by a threedimensional recirculation region of low velocities. The distribution of pressure inside the domain shows the correct physical trends. High pressures are observed around the upstream fluidporous interface due to the airflow impingement on the porous material, while low pressures are predicted in the wake.

The moisture content distribution inside the apple slice at different instants in time is presented in Fig. 6, which shows that the moisture content inside the apple gradually reduces as the drying process proceeds in time. The local distribution of moisture content further reveals that, at a given time, the lowest moisture content is correctly observed in the vicinity of the fluid-porous interfaces. Furthermore, the moisture content gradually increases towards the inner region of the porous material as described earlier.

A key feature of the present formulation is its capability to model the evaporation of water during the drying process. To illustrate this influence, Fig. 7 shows the domain relative humidity and fluid temperature at an integrated moisture content of 0.6. The relative humidity contours indicate that the relative humidity inside the porous region is higher compared to the surrounding airflow region. Higher relative humidity inside the porous region is attributed to the interfacial moisture transfer occurring inside the porous media. Moreover, the relative humidity of the porous region further increases due to increasing incoming airflow relative humidity. It is interesting to note that the margin of the porous region's relative humidity increment grows with rising incoming airflow relative humidity. Such behavior can be explained by the resistance coefficient, $C_{f}$. As the incoming airflow relative humidity increases, the value of $C_{f i}$ rises, which hinders the vapour loss from the fluid-constituent resulting in higher vapour pressure and relative humidity inside the porous region.

The fluid temperature distribution in Fig. 7 indicates cooling of the fluid inside the porous region, which is due to evaporative cooling. The level of evaporative cooling is correctly captured with the present model. For example, the case of $100 \%$ inlet airflow relative humidity correctly produces no cooling, despite the porous region being completely saturated with vapour. As the relative humidity of the incoming airstream is reduced (for a fixed initial moisture content in the apple), the porous apple is shown to cool more and more.

\section{Summary}

In the present study, convective drying of porous materials was modeled using a conjugate domain approach, which involves modeling the porous material and the surrounding airflow (fluid region). The proposed framework is general and can be utilized to simulate the drying process of a wide range of porous materials under different drying conditions. The proposed model includes mass and momentum, energy, and moisture transport equations in both the fluid and porous regions. Inside the porous material, both the liquid water and water vapour transport was considered by utilizing the non-equilibrium heat and moisture transfer approach. Mathematical conditions at the fluid-porous interface were enforced to ensure the smooth transfer of momentum, energy and moisture across the interface. Additional modeling was carried out in the fluid region adjacent to the interface to develop the airflow moisture threshold, and in the porous region adjacent to the interface to ensure the model accuracy. In this respect, detailed discussion of interfacial moisture transfer condition was made using electric circuit analogy.

The proposed model was validated by considering apple flesh as a porous material. In this respect, detailed modeling of the apple was required. The solid-structure holding water was considered as the solid-constituent, while the fluid-constituent was occupied by the moist air voids. The present study evaluated the missing apple properties such as solid-structure density and mass fraction, and moisture diffusivity coefficients required to simulate the unsteady convective drying process. The predicted moisture content was found to deviate against the experimental data by a maximum of $3 \%$ in time for the airflow velocity range of $0.64-2.75 \mathrm{~m} / \mathrm{s}$. Moreover, the results of local distribution of velocity, pressure, temperature, and moisture content inside the domain were also found to be physically realistic. In this respect, we have demonstrated that a conjugate, non-equilibrium model can provide information necessary to make the next important step towards direct, dynamic coupling of the phases.

Supplementary video related to this article can be found at http://dx.doi.org/10.1016/j.jfoodeng.2016.01.029.

\section{Acknowledgments}

The authors gratefully acknowledge the financial support from the Natural Sciences and Engineering Research Council of Canada (NSERC).

\section{References}

Akpinar, E., Midilli, A., Bicer, Y., 2003. Single layer drying behaviour of potato slices in a convective cyclone dryer and mathematical modeling. Energy Convers, Manag. 44 (10), 1689-1705.

Ateeque, M., Mishra, R.K., Chandramohan, V.P., Talukdar, P., 2014. Numerical modeling of convective drying of food with spatially dependent transfer coefficient in a turbulent flow field. Int. J. Therm. Sci. 78, 145-157. 
Barati, E., Esfahani, J.A., 2011a. A new solution approach for simultaneous heat and mass transfer during convective drying of mango. J. Food Eng. 102 (4), 302-309.

Barati, E., Esfahani, J.A., 2011b. Mathematical modeling of convective drying: lumped temperature and spatially distributed moisture in slab. Energy 36 (4), 2294-2301.

Barati, E., Esfahani, J.A., 2013. A novel approach to evaluate the temperature during drying of food products with negligible external resistance to mass transfer. J. Food Eng. 114 (1), 39-46.

Betchen, L., Straatman, A.G., Thompson, B.E., 2006. A nonequilibrium finite-volume model for conjugate fluid/porous/solid domains. Numer. Heat. Transf. Part A Appl. 49 (6), 543-565.

Bird, R.B., Stewart, W.E., Lightfoot, E.N., 2007. Transport Phenomena, second ed. (New York, NY).

Calmidi, V.V., Mahajan, R.L., 2000. Forced convection in high porosity metal foams. J. Heat Transf. 122 (3), 557-565.

Cengel, Y.A., Boles, M.A., 2008. Thermodynamics an Engineering Approach, sixth ed., pp. 738-747 (New York, NY).

De Bonis, M.V., Ruocco, G., 2008. A generalized conjugate model for forced convection drying based on an evaporative kinetics. J. Food Eng. 89 (2), 232-240.

Defraeye, T., Blocken, B., Derome, D., Nicolai, B., Carmeliet, J., 2012a. Convective heat and mass transfer modelling at air-porous material interfaces: overview of existing methods and relevance. Chem. Eng. Sci. 74, 49-58.

Defraeye, T., Blocken, B., Carmeliet, J., 2012b. Analysis of convective heat and mass transfer coefficients for convective drying of a porous flat plate by conjugate modelling. Int. J. Heat Mass Transf. 55 (1), 112-124.

Demir, V., Gunhan, T., Yagcioglu, A.K., 2007. Mathematical modelling of convection drying of green table olives. Biosyst. Eng. 98 (1), 47-53.

Donsi, G., Ferrari, G., Nigro, R., 1996. Experimental determination of thermal conductivity of apple and potato at different moisture contents. J. Food Eng. 30 (3), 263-268.

Erriguible, A., Bernada, P., Couture, F., Roques, M., 2006. Simulation of convective drying of a porous medium with boundary conditions provided by CFD. Chem. Eng. Res. Des. 84 (2), 113-123.

Esfahani, J.A., Majdi, H., Barati, E., 2014. Analytical two-dimensional analysis of the transport phenomena occurring during convective drying: apple slices. J. Food Eng. 123, 87-93.

Feng, H., Tang, J., Plumb, O.A., Cavalieri, R.P., 2004. Intrinsic and relative permeability for flow of humid air in unsaturated apple tissues. J. Food Eng. 62 (2), 185-192.

Golestani, R., Raisi, A., Aroujalian, A., 2013. Mathematical modeling on air drying of apples considering shrinkage and variable diffusion coefficient. Dry. Technol. 31 (1), 40-51.

Incropera, F., Dewitt, D., Bergman, T., Lavine, A., 2006. Fundamentals of Heat and Mass Transfer, fifth ed., p. 927 (Hoboken, NJ).

Kaviany, M., 1995. Principles of Heat Transfer in Porous Media, second ed. (New York, NY).

Kaya, A., Aydın, O., Dincer, I., 2006. Numerical modeling of heat and mass transfer during forced convection drying of rectangular moist objects. Int. J. Heat Mass Transf. 49 (17), 3094-3103.

Khan, F.A., Fischer, C., Straatman, A.G., 2015. Numerical model for non-equilibrium heat and mass exchange in conjugate fluid/solid/porous domains with application to evaporative cooling and drying. Int. J. Heat Mass Transf. 80, 513-528.

Kumar, C., Karim, A., Joardder, M.U.H., Miller, G., 2012, November. Modeling heat and mass transfer process during convection drying of fruit. In: The 4th International Conference on Computational Methods (ICCM2012).

Lamnatou, C., Papanicolaou, E., Belessiotis, V., Kyriakis, N., 2010. Finite-volume modelling of heat and mass transfer during convective drying of porous bodies-Non-conjugate and conjugate formulations involving the aerodynamic effects. Renew. Energy 35 (7), 1391-1402.

Lozano, J.E., Rotstein, E., Urbicain, M.J., 1980. Total porosity and open-pore porosity in the drying of fruits. J. Food Sci. 45 (5), 1403-1407.

Menges, H.O., Ertekin, C., 2006. Mathematical modeling of thin layer drying of Golden apples. J. Food Eng. 77 (1), 119-125.

Mohan, V.C., Talukdar, P., 2010. Three dimensional numerical modeling of simultaneous heat and moisture transfer in a moist object subjected to convective drying. Int. J. Heat Mass Transf. 53 (21), 4638-4650.

Murugesan, K., Suresh, H.N., Seetharamu, K.N., Narayana, P.A., Sundararajan, T., 2001. A theoretical model of brick drying as a conjugate problem. Int. J. Heat Mass Transf. 44 (21), 4075-4086.

Mykhailyk, V., Lebovka, N., 2014. Specific heat of apple at different moisture contents and temperatures. J. Food Eng. 123, 32-35.

Nist, (2011). Water Antoine Equation Parameters. The National Institute of Standards and Technology (NIST), available from: <http://webbook.nist.gov/cgi/ cbook.cgi? ID=C7732185\&Mask=4\&Type=ANTOINE\&Plot $=$ on $>$.

O'Neill, M.B., Rahman, M.S., Perera, C.O., Smith, B., Melton, L.D., 1998. Color and density of apple cubes dried in air and modified atmosphere. Int. J. Food Prop. 1 (3), 197-205.

Perré, P., Turner, I.W., 1999. A 3-D version of TransPore: a comprehensive heat and mass transfer computational model for simulating the drying of porous media. Int. J. Heat Mass Transf. 42 (24), 4501-4521.

Perussello, C.A., Kumar, C., de Castilhos, F., Karim, M.A., 2014. Heat and mass transfer modeling of the osmo-convective drying of yacon roots (Smallanthus sonchifolius). Appl. Therm. Eng. 63 (1), 23-32.
Rahman, M.S., 1995. Handbook of Food Properties (Boca Raton, FL).

Sabarez, H.T., 2012. Computational modelling of the transport phenomena occurring during convective drying of prunes. J. Food Eng. 111 (2), 279-288.

Seiiedlou, S., Ghasemzadeh, H.R., Hamdami, N., Talati, F., Moghaddam, M., 2010 Convective drying of apple: mathematical modeling and determination of some quality parameters. Int. J. Agric. Biol. 12 (2), 171-178.

Sereno, A.M., Silva, M.A., Mayor, L., 2007. Determination of particle density and porosity in foods and porous materials with high moisture content. Int. J. Food Prop. 10 (3), 455-469.

Srikiatden, J., Roberts, J.S., 2005. Moisture loss kinetics of apple during convective hot air and isothermal drying. Int. J. Food Prop. 8 (3), 493-512.

Srikiatden, J., Roberts, J.S., 2008. Predicting moisture profiles in potato and carrot during convective hot air drying using isothermally measured effective diffusivity. J. Food Eng. 84 (4), 516-525.

Stanish, M.A., Schajer, G.S., Kayihan, F., 1986. A mathematical model of drying for hygroscopic porous media. AIChE J. 32 (8), 1301-1311.

Steeman, H.J., Van Belleghem, M., Janssens, A., De Paepe, M., 2009. Coupled simulation of heat and moisture transport in air and porous materials for the assessment of moisture related damage. Build. Environ. 44 (10), 2176-2184.

Suresh, H.N., Narayana, P.A. Seetharamu, K.N., 2001. Conjugate mixed convection heat and mass transfer in brick drying. Heat Mass Transf. 37 (2-3), 205-213.

Tsilingiris, P.T., 2008. Thermophysical and transport properties of humid air at temperature range between 0 and 100 C. Energy Convers. Manag. 49 (5), $1098-1110$.

Tzempelikos, D.A., Mitrakos, D., Vouros, A.P., Bardakas, A.V., Filios, A.E. Margaris, D.P., 2015. Numerical modeling of heat and mass transfer during convective drying of cylindrical quince slices. J. Food Eng. 156, 10-21.

Velić, D., Planinić, M., Tomas, S., Bilić, M., 2004. Influence of airflow velocity on kinetics of convection apple drying. J. Food Eng. 64 (1), 97-102.

Whitaker, S., 1997. Volume Averaging of Transport Equations. chap. 1, Fluid Transport in Porous Media, pp. 1-59 (Southampton, UK).

Younsi, R., Kocaefe, D., Poncsak, S., Kocaefe, Y., 2006. Thermal modelling of the high temperature treatment of wood based on Luikov's approach. Int. J. Energy Res. 30 (9), 699-711.

Younsi, R., Kocaefe, D., Poncsak, S., Kocaefe, Y., Gastonguay, L., 2008. CFD modeling and experimental validation of heat and mass transfer in wood poles subjected to high temperatures: a conjugate approach. Heat Mass Transf. 44 (12), 1497-1509.

Yu, Q., Thompson, B.E., Straatman, A.G., 2006. A unit cube-based model for heat transfer and fluid flow in porous carbon foam. J. Heat Transf. 128 (4), 352-360.

\section{Nomenclature}

\section{A: area, $\mathrm{m}^{2}$}

$A_{f s}$ : specific interfacial surface area of porous media, $\mathrm{m}^{-1}$

$C_{E}$ : inertia coefficient of porous media

$c_{p}$ : specific heat at constant pressure in fluid region, $\mathrm{J} /(\mathrm{kg} . \mathrm{K})$

$c_{p s}$ : specific heat in solid region, $\mathrm{J} /(\mathrm{kg} . \mathrm{K})$

$D$ : binary diffusivity coefficient, $\mathrm{m}^{2} / \mathrm{s}$

$d_{p}$ : pore diameter, $\mu \mathrm{m}$

$f$ : body force per unit mass, $\mathrm{m} / \mathrm{s}^{2}$

$h$ : specific enthalpy, $\mathrm{J} / \mathrm{kg}$

$h_{f g}$ : latent heat of evaporation at $0{ }^{\circ} \mathrm{C}$ in fluid region, $\mathrm{J} / \mathrm{kg}$

$h_{f s}$ : interfacial heat transfer coefficient in porous media, $\mathrm{W} /\left(\mathrm{m}^{2} \mathrm{~K}\right)$

$h_{f s m}$ : interfacial mass transfer coefficient in porous media, $\mathrm{m} / \mathrm{s}$

$k$ : thermal conductivity, $\mathrm{W} /(\mathrm{m} \mathrm{K})$

$K$ : Darcy permeability of porous media, $\mathrm{m}^{2}$

m: mass, $\mathrm{kg}$

$\dot{m}:$ mass flow rate, $\mathrm{kg} / \mathrm{s}$

$\boldsymbol{n}$ : outward normal unit vector

$\mathrm{Nu}$ : Nusselt number

$P$ : pressure, $\mathrm{Pa}$

Pr: Prandtl number

$R$ : gas constant, $\mathrm{J} /(\mathrm{kg} . \mathrm{K})$

$R e$ : Reynolds number

$S$ : source in a transport equation

Sc: Schmidt number

Sh: Sherwood number

$T$ : temperature, ${ }^{\circ} \mathrm{C}$

$U_{\infty}$ : freestream velocity, $\mathrm{m} / \mathrm{s}$

$t$ : time, $\mathrm{s}$

$\boldsymbol{v}$ : fluid velocity $[=(u, v, w)], \mathrm{m} / \mathrm{s}$

$X$ : moisture content, $\mathrm{kg}$ water $/ \mathrm{kg}$ dry matte

$Y$ : mass fraction

$\alpha$ : volume fraction

$\mu$ : dynamic viscosity, N.s $/ \mathrm{m}^{2}$

$\rho_{\mathrm{s}}$ : density of solid, $\mathrm{kg} / \mathrm{m}^{3}$

$\rho_{f}$ : density of fluid mixture, $\mathrm{kg} / \mathrm{m}^{3}$

$\varepsilon$ : porosity

$\varphi$ : a quantity

$\langle\varphi\rangle$ : extrinsic volume-average of $\varphi$ 
$\langle\varphi\rangle^{x x}$ : Intrinsic volume-average of $\varphi(x$ is fluid or solid-constituent of porous media) subscripts and superscripts

a: air

$e$ : energy eff: effective property in porous media

$f$ : fluid

$f l$ : fluid side of interface

por: porous side of interface

$v$ : vapour

$w$ : water 